\title{
Borrelia burgdorferi
}

National Cancer Institute

\section{Source}

National Cancer Institute. Borrelia burgdorferi. NCI Thesaurus. Code C76208.

A species of bacteria within the phylum Spirochaetes that is the causative agent of Lyme disease. 